\title{
Thermodynamic Characterization of Undefined Petroleum Fractions of Gas Condensate using Group Contribution
}

\author{
Veronica Uribe-Vargas*, Bernardo Carreón-Calderón, Edgar Ramírez-Jaramillo \\ and Mario Ramírez-de-Santiago \\ Mexican Institute of Petroleum, Mexico City - Mexico \\ e-mail: vuribe@imp.mx - bcarreon@imp.mx - eramirez@imp.mx - msantiag@imp.mx \\ * Corresponding author
}

\begin{abstract}
A methodology proposed in a previous paper [Carreón-Calderón et al. (2012) Ind. Eng. Chem. Res. 51, 14188-14198] for thermodynamic characterization of undefined petroleum fractions was applied to gas-condensate fluids. Using this methodology, input parameters of cubic equations of state and their mixing rules, critical properties and chemical pseudostructures are determined for undefined fractions by minimizing their Gibbs free energy. The results show the feasibility of applying this approach to gas-condensate fluids without making use of either cubic equations of state or mixing rules with specific adjusted parameters for petroleum fluids. Besides, it is shown that the phase equilibrium envelopes of gas-condensate fluids are highly dependent on the critical properties assigned to the undefined petroleum fractions of such fluid fractions and less dependent on the equation used for modeling gas-condensate fluids as a whole. The Absolute Average Error (AAE) considering the best arrangement is $1.79 \%$ in predicting the dew point.
\end{abstract}

Résumé - Caractérisation thermodynamique des fractions indéfinies d'un condensat de gaz à l'aide de la méthode de contribution de groupes - Une méthodologie proposée dans un article précédent [Carreón-Calderón et al. (2012) Ind. Eng. Chem. Res. 51, 14188-14198] pour la caractérisation thermodynamique des fractions de pétrole non définies a été appliquée à des gaz à condensats. En utilisant cette méthodologie, les paramètres d'entrée de l'équation d'état cubique et leurs règles de mélange, propriétés critiques et pseudo-structures chimiques, sont déterminés pour les fractions non définis en minimisant l'énergie libre de Gibbs. Les résultats montrent que l'application de cette approche est appropriée aux fluides provenant des condensats de gaz sans utiliser, pour l'équation d'état cubique ou les règles de mélange, de paramètres caractéristiques ajustés pour les fluides pétroliers. En plus, il est montré que les courbes d'équilibre de phases des fluides de condensat de gaz sont fortement dépendantes des propriétés critiques associées aux fractions de pétrole non définies et moins dépendantes de l'ensemble des équations modélisant les fluides de condensat de gaz. Pour la prédiction du point de rosée, l'erreur moyenne absolue est $1,79 \%$ pour le meilleur arrangement. 


\section{NOTATION}

AAD Absolute Average Deviation

$F G \quad$ Number of functional group types

$J R \quad$ The Joback-Reid method

$M W \quad$ Molecular weight

MHV1 Modified Huron-Vidal mixing rule of one parameter

$P \quad$ Pressure (MPa)

$P_{C} \quad$ Critical pressure $(\mathrm{MPa})$

$p_{c} \quad$ Contribution to $P_{c}$ by functional groups

PSRK Predictive Soave-Redlich-Kwong mixing rule

$P R \quad$ Peng-Robinson equation of state

$R \quad$ Gas constant, $8.31441 \mathrm{~J} / \mathrm{mol} . \mathrm{K}$

SRK Soave-Redlich-Kwong equation of state

$T \quad$ Temperature (K)

$T_{b} \quad$ Boiling temperature at $0.101325 \mathrm{MPa}(\mathrm{K})$

$T_{c} \quad$ Critical temperature $(\mathrm{K})$

$t_{c} \quad$ Contribution to $T_{c}$ by functional groups

$V \quad$ Volume $\left(\mathrm{m}^{3} / \mathrm{mole}\right)$

$V_{c} \quad$ Critical volume $\left(\mathrm{m}^{3} / \mathrm{mol}\right)$

$V D W$ van der Waals mixing rule

$v_{c} \quad$ Contributions to $V_{c}$ by functional groups

$x \quad$ Mole fraction

$Z_{c} \quad$ Critical compressibility factor

\section{GREEK LETTERS}

$\alpha \quad$ Coefficient in Equation (14)

$\beta \quad$ Coefficient in Equation (14)

$\chi \quad$ Coefficient in Equation (14)

$\Delta v \quad$ Group volume increment, Equation (13)

$\phi \quad$ Fugacity coefficient

$\gamma \quad$ Activity coefficient

$\rho \quad$ Mass density $\left(\mathrm{kg} / \mathrm{m}^{3}\right)$

$v \quad$ Number of functional groups

$\omega \quad$ Acentric factor

\section{SUPERSCRIPTS}

$\begin{array}{ll}E O S & \text { Equation Of State } \\ \text { EXP } & \text { Experimental value }\end{array}$

\section{SUBSCRIPTS}

c Critical property

$i \quad$ Functional group $i$ or pure component $i$

$k \quad$ Undefined petroleum fraction $k$ or pure component $k$

\section{INTRODUCTION}

Gas-condensate fluids from reservoirs are composed of hydrocarbon compounds from $\mathrm{C}_{1}$ to $\mathrm{C}_{6}$ and at least one undefined fraction, containing unidentified compounds ranging from $\mathrm{C}_{7}$ to heavier hydrocarbon compounds. Similar to other petroleum fluids, gascondensate fluids are very complex to model, not only because of the presence of unidentified compounds but also because of the presence of non-hydrocarbon compounds such as hydrogen sulfide, carbon dioxide and nitrogen.

In the same way as heavier petroleum fluids, the characterization of undefined fractions has a great effect on phase equilibrium simulations of gas-condensate fluids. Several methods have been proposed for characterizing undefined fractions, where experimental information in the form of molar distributions, the mole fraction against the Carbon Number $(\mathrm{CN})$, is taken as starting point. For instance, it has been observed that a single straight-line relationship exists between the logarithm of the mole fraction and the molecular weight of the CN (Ahmed, 1989; Hosein and McCain, 2007). On the other hand, Whitson $(1983,1984)$ used a gamma distribution to establish the molar distribution. Soreide (1989) modified Whitson's method using a $K$ factor in order to generate the distribution of specific gravities. When an experimental molar distribution of undefined fractions is absent, the methods commonly employed in the oil industry are those given by Whitson et al. (1990) and Pedersen et al. (1992).

Once the molar distribution has been defined, the characterization procedure requires the estimation of the critical properties for each $\mathrm{CN}$ or a mixture of them. Such mixtures are better known as pseudocomponents. The estimation of critical properties is usually performed using empirical correlations. Some examples of such correlations are those obtained by Kesler and Lee (1976) and Pedersen et al. (1980) among others. Sinayuc and Gumrah (2004) established that different sets of correlations provide very dissimilar results. These differences may be explained by the fact that the empirical correlations are obtained from specific experimental data banks of pure compounds; hence, they cannot be used in a general way irrespective of the type of petroleum fraction under study. On the other hand, attempts have been made to obtain a more generalized methodology. For instance, Sinayuc and Gumrah (2004) proposed an optimization method that consists of finding the global minimum of Gibbs energy using critical properties obtained from correlations as independent variables and a genetic algorithm as an optimization tool. 
Recently, Carreón-Calderón et al. (2012) proposed a methodology, the so-called CURR (Carreón-UribeRamírez-Ramírez's) approach, to estimate the critical properties of undefined petroleum fractions using an approach based on group contribution methods. Using classical thermodynamics, a molecular pseudostructure and critical properties are assigned to a given undefined petroleum fraction by minimizing its corresponding free energy. The CURR approach was applied to light petroleum fluids, where an experimental molar distribution was available. The results obtained appeared to be acceptable, irrespective of both the equation of state and the mixing rule used. Hence, the aim of this work is to test the functionality of the CURR approach under more difficult situations; for example, when an experimental molar distribution is not provided and therefore it has to be estimated, which is usually the case of gascondensate fluids.

\section{METHODOLOGY}

The CURR approach was described in detail in a previous work (Carreón-Calderón et al., 2012). In that methodology, one molecular pseudostructure, a set of non-integer functional groups, is simultaneously determined for a given petroleum fraction of unknown composition. Such properties allow undefined petroleum fractions to be treated as hypothetical pure components. This means that any method developed for handling components with known molecular structure can now be applied to petroleum mixtures containing undefined petroleum fractions. Thus, petroleum fluids, which are mixtures formed of unidentified compounds mostly, turn into mixtures formed of identified and pseudocompounds.

It should be noted that this procedure has been evaluated for the characterization of undefined fractions of light petroleum, where their corresponding experimental molar distributions were available. Hence, in this work, an additional step to estimate this distribution is included because experimental molar distributions are not provided for the condensate-gas fluids under study. As will be seen in what follows, this estimation consists of splitting the heavy undefined petroleum fraction, the $\mathrm{C}_{7}$ fraction, into carbon numbers by assuming a probability distribution. In Figure 1, starting with such an estimation, the stages of the CURR method described in the following sections are summarized.

\subsection{Molar Distribution of the Heavy Fraction $\left(\mathrm{C}_{7+}\right)$}

Pedersen et al. (1992) proposed that, for naturallyoccurring hydrocarbon mixtures, an exponential

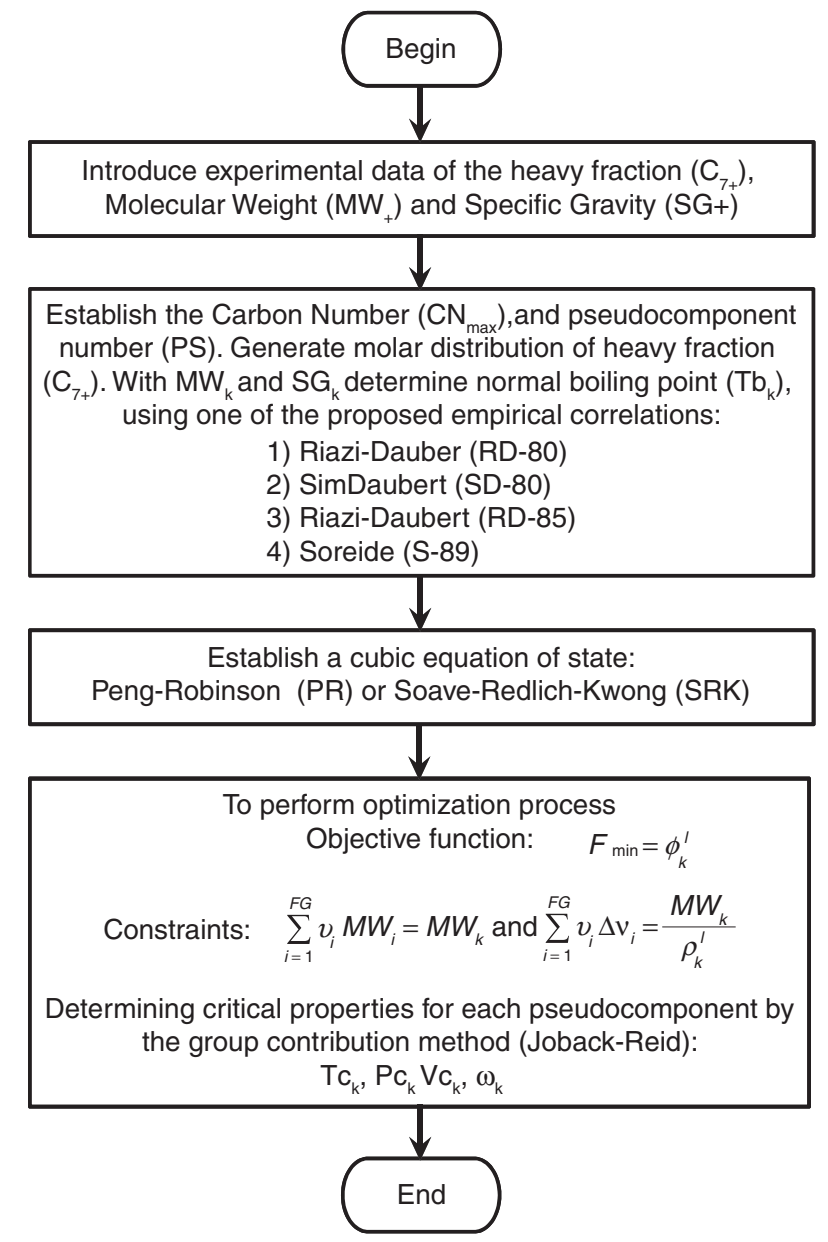

Figure 1

Flow diagram of the CURR method.

relation exists between the mole fraction of a component and the corresponding $\mathrm{CN}$. They expressed this relationship using the following expressions:

$$
\begin{gathered}
\ln x_{k}=A+B(C N)_{k} \\
\rho_{k}=C+D \ln (C N)_{k} \\
M W_{k}=14(C N)_{k}-4
\end{gathered}
$$

where $x_{k}$ symbolizes the mole fraction, $\rho_{k}$ the density, $M W_{k}$ the molecular weight and $(C N)_{k}$ the $k$-th carbon number. The heaviest carbon number is usually considered to be $\mathrm{CN}_{80}$. The constants $A, B, C$ and $D$ are determined from experimental values of the mole fraction, molecular weight and density of the heavy petroleum fraction $\mathrm{C}_{7+}$ together with mass balances as follows:

$$
x_{+}=\sum_{k=+}^{C N_{\max }} x_{k}
$$




$$
\begin{array}{r}
M W_{+}=\frac{\sum_{k=+}^{C N_{\max }} x_{k} M W_{k}}{x_{+}} \\
\rho_{+}=\frac{x_{+} M W_{+}}{\sum_{k=+}^{C N_{\max }} \frac{x_{k} M W_{k}}{\rho_{k}}}
\end{array}
$$

The subscript + indicates properties of the $\mathrm{C}_{7+}$ fraction to be split up. These expressions allow calculating the mole fraction, the molecular weight and the liquid density for each carbon number (Pedersen and Christensen, 2007). In order to solve the system of equations, it is considered that Equation (1) can be equally written in terms of the molecular weight instead of the carbon number, that is:

$$
\ln x_{k}=A+B M W_{k}
$$

If this equation is inserted into Equations (4) and (5), and Equation (3) is used to determine the molecular weight for each carbon number $k\left(M W_{k}\right)$, then we have a system of two equations with two unknowns ( $A$ and $B)$. This system can be solved by any numerical method, such as Newton-Raphson. A similar procedure is performed for determining the liquid density for each carbon number $k$ from the liquid density of the $\mathrm{C}_{7+}$ fraction through Equation (2) and Equation (6), but in this case, the previously determined molar distribution, $M W_{k}$ against $x_{k}$, is used together with the density of the last carbon number fraction before the $\mathrm{C}_{7+}$ fraction, that is, the $n$-hexane liquid density. Once the molar distribution has been determined, the characterized petroleum fluid is formed by 80 carbon numbers and defined compounds. Hence, it is advisable to lump carbon numbers into pseudocomponents to reduce the total number of components, and consequently to make the phase equilibrium calculations easier. In Pedersen's methodology, a weight-based grouping is recommended, where each group (pseudocomponent) contains approximately the same weight amount. However, unlike Pedersen's methodology, where critical properties are found as weight mean averages, in this work, they are found from the density, molecular weight and boiling temperature of each pseudocomponent directly by the minimization procedure described below.

\subsection{Determination of the Molecular Pseudostructure}

In this step, one hypothetical structure, set, is noninteger functional groups are assigned to each pseudocomponent. This molecular pseudostructure may not correspond to the actual structure obtained from experimental data, but it is expected that it allows properties entering into cubic equations of state to be estimated correctly.

\section{Critical Properties and Liquid Density Group Contribution}

Estimating critical properties and the acentric factor from known chemical structure is the greatest advantage of group contribution methods. There have been various proposals for their application to characterize petroleum; for example, Ruzicka et al. (1983) and Avaullee et al. (1997a-c, 2001). In the latter works, one molecular pseudostructure is assigned to the $\mathrm{C}_{20}+$ fraction by solving systems of equations developed for a fixed set of noninteger functional groups, whereas, starting with the knowledge of paraffinic-naphthenic-aromatic analysis, two or three key compounds are used to represent undefined fractions from $\mathrm{C}_{6}$ to $\mathrm{C}_{19}$. For every undefined fraction, either one pseudostructure or key compounds are found by matching the experimental molecular weight and molar volume to calculations. Although the PR equation of state is also employed with $\mathrm{C}_{6}$ to $\mathrm{C}_{19}$ fractions for such a purpose, it is worth pointing out that, unlike the current treatment, in those studies any minimization procedure subject to constraints was not suggested in order to obtain optimized functional groups in accordance with the thermodynamic laws. This issue allows, in principle, any group contribution method to be used in the current characterization procedure, as will be shown in future work.

Group contribution methods applied to a wider variety of chemical species have been developed to estimate the properties of a pure compound; for example, those proposed by Jöback and Reid (1987) (JR), and by Marrero and Gani (2001). In the current work, the former is suggested to be employed for estimating critical properties $\left(T_{c}, P_{c}\right.$ and $\left.V_{c}\right)$ of pseudocomponents; the respective expressions are:

$$
\begin{gathered}
T_{c}=\frac{T_{b}}{0.584+0.965 \sum_{i=1}^{F G} \mathrm{v}_{i} t_{c i}-\left(\sum_{i=1}^{F G} \mathrm{v}_{i} t_{c i}\right)^{2}} \\
P_{c}=\frac{0.1}{\left(0.113+0.0032 n_{A}-\sum_{i=1}^{F G} \mathrm{v}_{i} p_{c i}\right)^{2}} \\
V_{c}=\frac{17.5+\sum_{i=1}^{F G} \mathrm{v}_{i} v_{c i}}{10^{6}}
\end{gathered}
$$


TABLE 1

Correlations for estimating normal boiling point

\begin{tabular}{c|c|c}
\hline & Normal boiling point & Source \\
\hline RD80 & $T_{b}=\frac{5}{9}\left[\left(\frac{M W \times S G^{1.0164}}{4.5673 \times 10^{-5}}\right)^{\frac{1}{2.1962}}\right]$ & Riazi and Daubert (1980) \\
\hline SD80 & $T_{b}=\frac{5}{9}\left[\left(\frac{M W \times S G^{0.9371}}{1.4350476 \times 10^{-5}}\right)^{\frac{1}{2.3776}}\right]$ & Sim and Daubert (1980) \\
\hline RD87 & $T_{b}=\frac{5}{9}\left[6.77857 \times M W^{0.401673} S G^{-1.58262} E X P\left(3.7741 \times 10^{-3} M W\right.\right.$ \\
S89 & $\left.\left.+2.984036 S G-4.25288 \times 10^{-3} S G\right)\right]$ & Riazi and Daubert (1987) \\
\hline
\end{tabular}

where $T_{c}, P_{c}$ and $V_{c}$ are the critical temperature, pressure and volume, respectively. Similarly, $t_{c i}, p_{c i}$ and $v_{c i}$ represent the corresponding contributions to $T_{c}, P_{c}$ and $V_{c}$ by the $i$-th functional group, being $\mathrm{v}_{i}$ the number of the functional groups of type $i$. In the above equations, $n_{A}$ is the number of atoms in the molecule, $T_{b}$ is the normal boiling point, and $F G$ is the total number of types of functional groups. The units for temperature, pressure and volume are $\mathrm{K}, \mathrm{MPa}$ and $\mathrm{m}^{3} / \mathrm{mol}$, respectively. As observed from Equation (7), the normal boiling point is required for the critical temperature to be calculated. Generally, the experimental value of such a boiling point is not available; consequently, the use of some empirical correlations found in the literature is recommended, which are displayed in Table 1 .

Another property required to calculate phase equilibrium calculations is the acentric factor. Unfortunately, in the JR method there is not any expression suggested; hence, in this work, we consider the following expression to estimate the acentric factor (Poling et al., 2001):

$$
\begin{gathered}
\omega=-\frac{\ln \left(P_{c} / 1.01325\right)+f_{0}\left(T_{b r}\right)}{f_{1}\left(T_{b r}\right)} \\
f_{0}\left(T_{b r}\right) \\
=\frac{-5.97616 \tau+1.29874 \tau^{1.5}-0.60394 \tau^{2.5}-1.06841 \tau^{5}}{T_{b r}} \\
f_{1}\left(T_{b r}\right) \\
=\frac{-5.03365 \tau+1.11505 \tau^{1.5}-5.41217 \tau^{2.5}-7.46628 \tau^{5}}{T_{b r}}
\end{gathered}
$$

$T_{b r}=T_{b} / T_{c}$ is the reduced normal boiling point and $\tau=1-T_{b r}$.
According to Equation (2), liquid density is part of the exponential molar distribution, which implies that a methodology based on functional groups is also required to estimate liquid densities. In the CURR approach, the liquid density of a given pseudocomponent is estimated by the group contribution method GCVOL (Group Contribution method for predicting Saturated Liquid Density) (Elbro et al., 1991; Ihmels and Gmehling, 2003), where the liquid density $\rho$ is calculated from:

$$
\rho=\frac{M W}{V}=\frac{M W}{\sum_{i=1}^{F G} v_{i} \Delta v_{i}}
$$

Here, $M W$ is the molecular weight and $\Delta v_{i}$ is the group volume increment expressed as a function of temperature as follows:

$$
\Delta v_{i}=\alpha_{i}+\beta_{i} T+\chi_{i} T^{2}
$$

where $\alpha_{i}, \beta_{i}$, and $\chi_{i}$ are specific parameters of a given functional group.

\section{Calculation of Functional Group Number}

In order to estimate the number of functional groups for an undefined petroleum fraction, either the carbon number or the pseudocomponent, each fraction is considered as an independent system at a fixed pressure and temperature. It is well known that the equilibrium of the Gibbs free energy has a minimum value at a fixed value of pressure and temperature. From the PVT experiments carried out in the petroleum industry, the temperature and pressure measurements established for this purpose are $288.7 \mathrm{~K}\left(60^{\circ} \mathrm{F}\right)$ and $0.1013 \mathrm{MPa}(1 \mathrm{~atm})$. Thus, starting with the residual Gibbs energy, it was shown in the CURR approach that the above assumptions lead to 
minimizing the liquid fugacity coefficient of the respective undefined petroleum fraction (pseudocomponent), which is treated as a hypothetical pure compound. In other words, the objective function to be minimized becomes:

$$
\begin{gathered}
\phi_{k}^{l}\left(T_{c k}\left(v_{1}, v_{2}, \ldots, v_{F G}\right), P_{c k}\left(v_{1}, v_{2}, \ldots, v_{F G}\right),\right. \\
\left.\omega_{k}\left(v_{1}, v_{2}, \ldots, v_{F G}\right)\right)
\end{gathered}
$$

Taking as constraints: the pseudocomponent volume expressed in Equation (13) and the corresponding molecular weight, expressed in turn by the following expression:

$$
\sum_{i=1}^{F G} \mathrm{v}_{i} M W_{i}=M W_{k}
$$

Using a cubic equation of state and the fundamental expression of fugacity coefficients, Equation (15) can be rewritten as:

$$
\begin{gathered}
\phi_{j}=-\ln (Z-B)+Z-1+\frac{A}{B(\gamma+\beta)} \ln \left(\frac{Z+B \gamma}{Z-B \gamma}\right) \\
\beta=\frac{\sqrt{u^{2}-4 w}-u}{2} \\
\gamma=\frac{\sqrt{u^{2}-4 w}+u}{2} \\
A=\frac{P a}{(R T)^{2}} \\
B=\frac{P b}{R T} \\
Z=\frac{P V}{R T}
\end{gathered}
$$

where $R$ is the gas constant. In the expressions above, $u$ and $w$ are parameters that depend on the equation of state, as shown in Table 2. On the other hand, $a$ and $b$ depend on the critical properties, as will be shown in the following section.

\subsection{PVT Property Calculation}

The cubic equations of state were chosen here because they are relatively simple mathematical models relating the pressure-volume-temperature behavior for fluid
TABLE 2

Equation of state parameters

\begin{tabular}{c|c|c}
\hline Parameter & PR & SRK \\
\hline$u$ & 2 & 1 \\
\hline$w$ & -1 & 0 \\
\hline$\Omega_{a}$ & $0.45724^{\mathrm{a}}$ & $0.42747^{\mathrm{b}}$ \\
\hline$\Omega_{b}$ & $0.07780^{\mathrm{a}}$ & $0.08664^{\mathrm{b}}$ \\
\hline$r_{1}$ & $0.37464^{\mathrm{a}}$ & $0.480^{\mathrm{b}}$ \\
\hline$r_{2}$ & $1.54226^{\mathrm{a}}$ & $1.574^{\mathrm{b}}$ \\
\hline$r_{3}$ & $-0.26992^{\mathrm{a}}$ & $-0.176^{\mathrm{b}}$ \\
\hline
\end{tabular}

${ }^{a}$ Peng and Robinson (1976).

${ }^{\mathrm{b}}$ Soave (1972).

phases, along with the fact that these equations have been used successfully in the oil industry. The PengRobinson (PR) (Peng and Robinson, 1976) and SoaveRedlich-Kwong (SRK) (Soave, 1972) equations of state were used in this work. The corresponding generalized expression is shown below:

$$
P=\frac{R T}{V-b}-\frac{a}{V^{2}+u b V-w b^{2}}
$$

The parameters $u$ and $w$ define the cubic equation of state; $v$ is the molar volume, while $a$ and $b$ are specific to a given component or, in the context of the current work, a given pseudocomponent through its critical properties, in accordance with the following expressions:

$$
\begin{gathered}
a=\frac{\Omega_{a}\left(R T_{c}\right)^{2} f}{P_{c}} \\
f=\left[1+\left(r_{1}+r_{2} \omega+r_{3} \omega^{2}\right)\left(1-\sqrt{\frac{T}{T_{C}}}\right)\right]^{2}
\end{gathered}
$$

$$
b=\frac{\Omega_{b} R T_{c}}{P_{c}}
$$

where $\Omega_{a}, \Omega_{b}$ and $r_{i}$ are specific parameters for each equation of state, as can be seen in Table 2. It is important to emphasize that Equations (7) and (8) along with Equations (24) to (26) connect functional groups of pseudocomponents with the fugacity coefficient for a pure compound given by either Equation (15) or Equation (17). 
TABLE 3

UNIFAC functional groups

\begin{tabular}{c|c|c}
\hline Chemical formula & Main group & Sub-group \\
\hline $\mathrm{CH}_{3}$ & 1 & 1 \\
\hline $\mathrm{CH}_{2}$ & 1 & 3 \\
\hline $\mathrm{CH}$ & 1 & 4 \\
\hline $\mathrm{C}$ & 1 & 9 \\
\hline $\mathrm{ACH}$ & 3 & 10 \\
\hline $\mathrm{AC}$ & 3 & 117 \\
\hline $\mathrm{CO}_{2}$ & 56 & 118 \\
\hline $\mathrm{CH}_{4}$ & 57 & 115 \\
\hline $\mathrm{N}_{2}$ & 60 & 114 \\
\hline $\mathrm{H}_{2} \mathrm{~S}$ & 61 & \\
\hline
\end{tabular}

Once one molecular structure and the critical properties are simultaneously determined for an undefined petroleum fraction (pseudocomponent) from the procedure described previously, the undefined petroleum fraction becomes a hypothetical pure component from the calculation standpoint. Thus, the whole mixture of hydrocarbons can be treated as a mixture of known components. This means that any approach developed for handling chemical structures can be applied to petroleum fluids regardless of the lack of experimental information about compounds forming undefined fractions and their chemical structures. To verify this assertion in the case of gas-condensate fluids, the Modified Huron-Vidal mixing rule of one parameter - MHV1 (Horstmann et al., 2005) using the group contribution method UNIFAC (Universal Functional group Activity Coefficients) as an activity coefficient model was used for PVT calculations. The set of UNIFAC functional groups used in the MHV1 mixing rule is shown in Table 3. In the same context, another mixing rule was used, the so-called Predictive Soave-Redlich-Kwong, PSRK (Horstmann et al., 2005). There are other mixing rules such as MHV2 (Dahl and Michelsen 1990), WongSandler (Wong and Sandler, 1992) a PPR78 (Jaubert and Mutelet, 2004; Jaubert et al., 2010), that have been proved to work adequately in predicting the equilibrium of hydrocarbon mixtures, but the aim of this study is to evaluate the CURR method's performance and not mixing rules in general. In other words, we intend to characterize undefined petroleum fractions of gas-condensate fluids so that models requiring chemical structures, the UNIFAC approach inserted into mixing rules in this case, can be employed with such fluids; something that is not routinely seen in phase equilibrium calculations involving petroleum because of the unknown numbers $v_{i}$. Otherwise, the so-called classical mixing rule or the Van Der Waals mixing rule (VDW) (Peng and Robinson, 1976; Soave, 1972), or its variations (Jaubert et al., 2010), is the only available mixing rule for performing such calculations. The reader is referred to the original paper (Carreón-Calderón et al., 2012) for additional information about the use of these mixing rules in the context of the CURR approach.

Although in the original CURR approach, correction in the molar volume was introduced by applying the concept of the volume translation (Peneloux et al., 1982) and GCVOL approach (Eq. 13), the concept of volume translation was not introduced here because the only calculations performed were the phase equilibrium ones. However, it is important to make a distinction between the liquid density of the pseudocomponent and the liquid density of the petroleum fluid as a whole. The former is required for determining the chemical pseudostructure of the corresponding pseudocomponent through the optimization problem given by Equation (15), whereas the latter is not required for phase equilibrium calculations.

\section{APPLICATIONS}

The methodology described previously was used first of all to characterize thermodynamically the undefined petroleum fraction of five gas-condensate fluids found in the literature. Then, inserting the calculated chemical pseudostructures and associated critical properties into the cubic equations of state and mixing rules described above, the phase equilibrium calculations were performed. The experimental data employed in this work are shown in Table 4.

As mentioned before, first, it is necessary to determine the exponential molar distribution from the only undefined petroleum fraction provided, the $\mathrm{C}_{7+}$ fraction in this case (Tab. 4), using the split method proposed by Pedersen. Thus, carbon numbers together with their corresponding molecular weight, specific gravity and molar fraction were obtained. These carbon numbers were then lumped together into pseudocomponents (PS) of approximately the same weight fraction.

As the next step, the critical properties were estimated for every pseudocomponent from the previous step through the minimization process of Gibbs energy given by Equation (15) and related expressions. As observed in Table 4, the boiling temperatures are not available, which, according to Equation (7), are required to estimate critical temperatures; consequently, empirical 
TABLE 4

Gas condensate composition, (Elsharkawy, 2002). Composition of the mole fraction. Density of the $\mathrm{C}_{7}+$ fraction is in $\mathrm{g} / \mathrm{cm}^{3}$

\begin{tabular}{|c|c|c|c|c|c|}
\hline Name & $\mathrm{GC} 1$ & $\mathrm{GC} 2$ & $\mathrm{GC} 3$ & $\mathrm{GC} 4$ & GC5 \\
\hline \multicolumn{6}{|c|}{ Mole fraction } \\
\hline $\mathrm{H}_{2} \mathrm{~S}$ & 0.0000 & 0.0000 & 0.0000 & 0.0001 & 0.0000 \\
\hline $\mathrm{CO}_{2}$ & 0.0000 & 0.0010 & 0.0095 & 0.0045 & 0.0098 \\
\hline $\mathrm{N}_{2}$ & 0.0000 & 0.0000 & 0.0077 & 0.0047 & 0.0066 \\
\hline $\mathrm{C}_{1}$ & 0.8238 & 0.9522 & 0.5980 & 0.6073 & 0.6810 \\
\hline $\mathrm{C}_{2}$ & 0.0428 & 0.0168 & 0.1415 & 0.1383 & 0.0700 \\
\hline $\mathrm{C}_{3}$ & 0.0351 & 0.0091 & 0.0689 & 0.0633 & 0.0505 \\
\hline$i-\mathrm{C}_{4}$ & 0.0161 & 0.0026 & 0.0140 & 0.0130 & 0.0179 \\
\hline$n-\mathrm{C}_{4}$ & 0.0303 & 0.0033 & 0.0252 & 0.0238 & 0.0198 \\
\hline$i-\mathrm{C}_{5}$ & 0.0060 & 0.0016 & 0.0102 & 0.0100 & 0.0162 \\
\hline$n-\mathrm{C}_{5}$ & 0.0068 & 0.0011 & 0.0119 & 0.0109 & 0.0108 \\
\hline $\mathrm{C}_{6}$ & 0.0099 & 0.0025 & 0.0175 & 0.0165 & 0.0177 \\
\hline $\mathrm{C}_{7+}$ & 0.0292 & 0.0098 & 0.0956 & 0.1076 & 0.0997 \\
\hline $\mathrm{MW}_{\mathrm{C} 7+}$ & 125 & 122.6 & 163 & 162 & 162 \\
\hline Density $_{\mathrm{C} 7+}$ & 0.74 & 0.723 & 0.791 & 0.789 & 0.807 \\
\hline Reservoir temperature $(\mathrm{K})$ & 278 & 378 & 416 & 416 & 398 \\
\hline DPP (MPa) & 21.345 & 23.069 & 28.986 & 28.779 & 35.993 \\
\hline
\end{tabular}

correlations were employed in accordance with Table 1. For illustrative purposes, the results obtained for the Gas Condensate 1 (GC1) are shown below, which correspond to the lowest Average Absolute Deviation (AAD) obtained for the Dew Point Pressure (DPP).

The molar distribution shown in Table 5 was carried out using $40 \mathrm{CN}$ which were then lumped into 12 pseudocomponents. The boiling temperature correlation employed was S89 (Tab. 1), and the equation of state used for the minimization procedure was PR, giving rise to the critical properties also shown in Table 5. Similarly, the numbers of functional groups obtained for GC1 with $\mathrm{CN}=40, \mathrm{PS}=12, \mathrm{~Tb}=\mathrm{S} 89$ and $\mathrm{EOS}=\mathrm{PR}$ are shown in Table 6 .

As shown in Table 6, the proposed methodology allows the values of the number of functional groups to be non-integer numbers, unlike what is considered in traditional methods of group contribution. It should be noted that these values are hypothetical; that is, they do not correspond to those obtained from experimental analysis; they represent the amount of energy and mass needed from such groups, so that the free energy is minimum. Ultimately, the aim of this work is to find structures that allow bulk properties to be estimated properly for phase equilibrium purposes.

Similarly to the results obtained by Carreón-Calderón et al. (2012), the numbers of functional groups shown in Table 6 are not distributed randomly; the same trends can be observed. For example, although incorporated simultaneously in calculations, some functional groups vanish for some pseudocomponents. It can be seen that the lightest pseudocomponents are characterized only by paraffinic functional groups, while cyclic and aromatic functional groups are incorporated into the molecular pseudostructure for the heavier pseudocomponents. In order to accomplish a sensitivity analysis of the different variables involved in the implementation of the CURR method, different tests for the five condensed gases under study were performed. To illustrate this, the results obtained for the condensate gas GC1 are shown in Table 7, where it can be seen that for different equations of state, mixing rules and numbers of pseudocomponents, the highest average absolute deviation is 3.75 for dew point pressure.

The results are similar to those obtained previously applying the CURR approach to light petroleum fluids, 
TABLE 5

Molar distribution and critical properties calculated in this work for GC1

\begin{tabular}{c|c|c|c|c|c|c|c}
\hline & \multicolumn{3}{|c|}{ Molar distribution } & \multicolumn{3}{c}{ Critical properties calculated } \\
\cline { 2 - 7 } & Mole fraction & MW & SG & $T_{c}(\mathrm{~K})$ & $P_{c}(\mathrm{MPa})$ & $V_{c}\left(\mathrm{~m}^{3} / \mathrm{mol}\right)$ & $\omega .0161 \mathrm{E}-04$ \\
\hline PS94 & 0.00908 & 94.0 & 0.6985 & 540.40 & 2.9563 & 0.3451 \\
\hline PS108 & 0.00626 & 108.0 & 0.7209 & 564.77 & 2.6760 & $4.5725 \mathrm{E}-04$ & 0.3941 \\
\hline PS122 & 0.00431 & 122.0 & 0.7375 & 588.40 & 2.4317 & $5.1300 \mathrm{E}-04$ & 0.4422 \\
\hline PS136 & 0.00297 & 136.0 & 0.7508 & 610.86 & 2.2209 & $5.6806 \mathrm{E}-04$ & 0.4859 \\
\hline PS150 & 0.00205 & 150.0 & 0.7619 & 642.37 & 2.1217 & $6.0459 \mathrm{E}-04$ & 0.4534 \\
\hline PS164 & 0.00141 & 164.0 & 0.7716 & 674.71 & 2.0619 & $6.3919 \mathrm{E}-04$ & 0.4119 \\
\hline PS178 & 0.00097 & 178.0 & 0.7801 & 694.20 & 1.9187 & $6.8979 \mathrm{E}-04$ & 0.4371 \\
\hline PS192 & 0.00067 & 192.0 & 0.7877 & 712.23 & 1.7901 & $7.4035 \mathrm{E}-04$ & 0.4617 \\
\hline PS206 & 0.00046 & 206.0 & 0.7946 & 728.96 & 1.6737 & $7.9055 \mathrm{E}-04$ & 0.4856 \\
\hline PS225 & 0.00054 & 225.7 & 0.8034 & 750.60 & 1.5277 & $8.6077 \mathrm{E}-04$ & 0.5175 \\
\hline PS258 & 0.00033 & 258.6 & 0.8162 & 782.72 & 1.3242 & $9.7779 \mathrm{E}-04$ & 0.5652 \\
\hline PS320 & 0.00016 & 321.0 & 0.8359 & 843.99 & 1.1560 & $1.1697 \mathrm{E}-03$ & 0.6104 \\
\hline
\end{tabular}

TABLE 6

Number of functional groups calculated for GC1, with 12 pseudocomponents

\begin{tabular}{|c|c|c|c|c|c|c|c|c|c|}
\hline & \multicolumn{9}{|c|}{ Number of functional groups $v$} \\
\hline & $-\mathrm{CH}_{3}$ & $-\mathrm{CH}_{2}$ & $>\mathrm{CH}-$ & $>\mathrm{C}<$ & $\begin{array}{l}-\mathrm{CH}_{2-} \\
\text { (cyclic) }\end{array}$ & $\begin{array}{l}>\mathrm{CH}- \\
\text { (cyclic) }\end{array}$ & $\begin{array}{c}>\mathrm{C}< \\
\text { (cyclic) }\end{array}$ & $\mathrm{ACH}$ & AC-C \\
\hline PS94 & 1.7752 & 4.7986 & 0 & 0 & 0 & 0 & 0 & 0 & 0 \\
\hline PS108 & 1.7236 & 5.8520 & 0 & 0 & 0 & 0 & 0 & 0 & 0 \\
\hline PS122 & 1.6962 & 6.8795 & 0 & 0 & 0 & 0 & 0 & 0 & 0 \\
\hline PS136 & 1.7966 & 7.6572 & 0.1215 & 0 & 0 & 0 & 0 & 0 & 0 \\
\hline PS150 & 3.1988 & 4.5371 & 1.6479 & 0 & 1.1983 & 0 & 0 & 0 & 0 \\
\hline PS164 & 3.7952 & 2.6892 & 1.5863 & 0.3940 & 2.7951 & 0 & 0 & 0.3554 & 0 \\
\hline PS178 & 4.0409 & 2.8788 & 1.7202 & 0.4690 & 2.9883 & 0 & 0 & 0.5315 & 0 \\
\hline PS192 & 4.2856 & 3.0683 & 1.8546 & 0.5453 & 3.1812 & 0 & 0 & 0.7073 & 0 \\
\hline PS206 & 4.5218 & 3.2470 & 1.9758 & 0.6060 & 3.3636 & 0.0707 & 0 & 0.8732 & 0 \\
\hline PS225 & 4.8435 & 3.4854 & 2.1312 & 0.6736 & 3.6076 & 0.2541 & 0 & 1.0945 & 0 \\
\hline PS258 & 5.3759 & 3.8823 & 2.3928 & 0.7924 & 4.0134 & 0.5612 & 0 & 1.4629 & 0 \\
\hline PS320 & 6.8420 & 3.9583 & 1.0824 & 0 & 4.2046 & 2.3387 & 3.2558 & 1.5336 & 0 \\
\hline
\end{tabular}


TABLE 7

Percent Absolute Average Deviation (AAD) of Dew Point Pressure (DPP), for gas condensate GC1

\begin{tabular}{|c|c|c|c|c|c|c|}
\hline \multirow[t]{2}{*}{ Equation of state } & \multirow[t]{2}{*}{ Mixing rule } & \multirow[t]{2}{*}{$\mathrm{Tb}$ correlation } & \multicolumn{4}{|c|}{ Pseudocomponent } \\
\hline & & & 1 & 6 & 12 & 18 \\
\hline & & & \multicolumn{4}{|c|}{$\%$ AAD } \\
\hline \multirow[t]{3}{*}{$\mathrm{PR}$} & VDW & \multirow{6}{*}{ S89 } & 3.08 & 0.21 & 0.52 & 0.33 \\
\hline & MHV1 & & 2.87 & 0.16 & 0.10 & 0.18 \\
\hline & PSRK & & 3.75 & 1.38 & 1.51 & 1.59 \\
\hline \multirow[t]{3}{*}{ RKS } & VDW & & 3.35 & 3.56 & 3.47 & 3.30 \\
\hline & MHV1 & & 2.68 & 2.83 & 2.73 & 2.62 \\
\hline & PSRK & & 1.52 & 1.25 & 1.43 & 1.12 \\
\hline
\end{tabular}

where any combination of cubic equations of state and mixing rules provided similar results provided that the properties of undefined petroleum fractions came from the minimization problem given by Equation (15) and related expressions. The possible explanation is that the CURR approach provides optimized properties, satisfying the fundamental thermodynamic relationships and the mass balance for every undefined petroleum fraction under study. Thus, the pressurevolume-temperature behavior predicted by any fluid model should improve by using such optimized properties.

The boiling point correlation used to determine the critical temperature has a higher impact on the phase envelope than both the cubic equation of state and the mixing rule, as shown in Figure 2. These results confirm that the pseudocomponent properties to be used in fluid models have a higher impact on the phase equilibrium prediction than the fluid model itself, at least in the case of cubic equations of state and their respective mixing rules. The Absolute Average Deviation (AAD) for Dew Point Pressure (DPP) for every case is shown in Table 8.

It should be noted that the results obtained with an exponential distribution employing 12 pseudocomponents had lower AAD than those obtained employing less pseudocomponents, which agrees with the results obtained by Elsharkawy (2002), who established that splitting up the plus fraction into 10 to 12 pseudocomponents leads to minimum absolute average relative deviation. Another interesting result from Table 8 is that, in contrast to Pedersen's suggestion, the best carbon number is not 80 ; the influence of the carbon number on phase envelope was undetectable for practical purposes. Finally, it can also be observed that the best results are

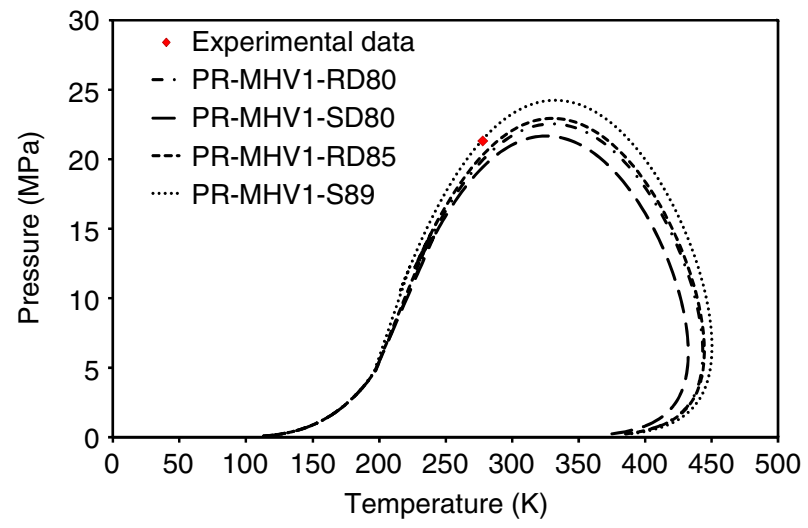

Figure 2

Phase envelope of CG1 using different correlations to estimate normal boiling temperature.

not always obtained using the same correlation for estimating boiling temperature, which shows again that properties to be used in cubic equations of state have a higher impact on the phase envelopes than the equations themselves.

Another aspect highlighted in the methodology shown in this work is that it is not necessary to adjust the parameters belonging to equations of state or their mixing rules in order to obtain a suitable estimation of the experimental data, as has been suggested elsewhere (Coats and Smart, 1986; Slot-Petersen, 1989; Merrill and Newley, 1993; Merrill et al., 1994). Besides, the information needed to characterize the undefined heavy fraction is small: the molecular weight and specific 
TABLE 8

Absolute Average Deviation (AAD) of equilibrium estimation of five gas condensates

\begin{tabular}{|c|c|c|c|c|c|c|c|}
\hline Fluid & $\begin{array}{c}\text { Mole } \\
\text { fraction } \mathrm{CH}_{4}\end{array}$ & $\begin{array}{l}\text { Mole fraction } \\
\qquad \mathrm{C}_{7+}\end{array}$ & $\mathrm{CH}_{4} / \mathrm{C}_{7+}$ & $\begin{array}{c}\text { Number of } \\
\text { pseudocomponents }\end{array}$ & $\mathrm{CN}$ & $\begin{array}{c}\mathrm{Tb} \\
\text { correlation }\end{array}$ & $\begin{array}{l}\text { AAD } \\
(\%)\end{array}$ \\
\hline $\mathrm{GC} 1$ & 0.8238 & 0.0292 & 28.21 & 12 & 40 & S89 & 0.10 \\
\hline $\mathrm{GC} 2$ & 0.9522 & 0.0098 & 97.16 & 12 & 40 & S89 & 1.65 \\
\hline GC3 & 0.598 & 0.0956 & 6.26 & 12 & 80 & SD80 & 2.18 \\
\hline GC4 & 0.6073 & 0.1076 & 5.64 & 12 & 80 & SD80 & 4.79 \\
\hline GC5 & 0.681 & 0.0997 & 6.83 & 12 & 80 & SD80 & 0.24 \\
\hline
\end{tabular}

gravity of just one undefined petroleum fraction: the $\mathrm{C}_{7+}$ fraction.

\section{CONCLUSIONS}

The results showed that the gas-condensate phase envelopes depend more on the properties assigned to the undefined heavy fraction than on the pressure-volumetemperature equations modeling such fluids. The procedure applied here provides optimized values of the critical properties and chemical pseudostructures. Thus, the choice of cubic equations of state or mixing rules with adjusted parameters is of little consequence to predict phase behavior properly.

It is also concluded that the CURR method of characterizing thermodynamically undefined heavy petroleum fractions of crude oil is also applicable for thermodynamic characterization of corresponding heavy fractions belonging to gas-condensate fluids, where experimental molar distribution is not provided. The experimental data required is minimal: the fluid global composition, and the molecular weight, specific gravity and the normal boiling point of the corresponding undefined heavy fraction.

\section{ACKNOWLEDGMENTS}

The authors thank the authorities of the Mexican Institute of Petroleum in Mexico City for permission to publish this work. Funding for this research from grant D.00432 is gratefully acknowledged.

\section{REFERENCES}

Ahmed T. (1989) Hydrocarbon phase behavior, Gulf Publishing Houston, pp. 356-359
Avaullee L., Trassy L., Neau E., Jaubert J.N. (1997a) Thermodynamic modeling for petroleum fluids I. Equation of state and group contribution for the estimation of thermodynamic parameters of heavy hydrocarbons, Fluid Phase Equilibria 139, 155-170.

Avaullee L., Neau E., Jaubert J.N. (1997b) Thermodynamic modeling for petroleum fluids II. Prediction of PVT properties of oils and gases by fitting one or two parameters to the saturation pressures of reservoir fluids, Fluid Phase Equilibria 139, 171-203.

Avaullee L., Neau E., Jaubert J.N. (1997c) Thermodynamic modeling for petroleum fluids III. Reservoir fluid saturation pressures. A complete PVT property estimation. Application to swelling test, Fluid Phase Equilibria 141, 87-104.

Avaullee L., Duchet-Suchaux P., Durandeau M., Jaubert J.N. (2001) A new approach in correlating the oil thermodynamic properties, Journal of Petroleum Science and Engineering 30, 43-65.

Carreón-Calderón B., Uribe-Vargas V., Ramírez Jaramillo E., Ramírez de Santiago M. (2012) Thermodynamic Characterization of Undefined Petroleum Fractions using Group Contribution Methods, Ind. Eng. Chem. Res. 51, 14188-14198.

Coats K.H., Smart G.T. (1986) Application of a regressionbased EOS PVT program to laboratory data, SPE Reservoir Eng. 1, 03, 277-299.

Dahl S., Michelsen M.L. (1990) High pressure vapour-liquid equilibrium with a UNIFAC-based equation of state, $A I C h E$ J. 36, 1829-1836.

Elsharkawy A.M. (2002) Predicting the dew point pressure for gas condensate reservoirs: empirical models and equations of state, Fluid Phase Equilib. 193, 147-165.

Elbro H.S., Fredenslund A., Rasmussen P. (1991) Group contribution method for the prediction of liquid densities as a function of temperature for solvents, oligomers, and polymers, Ind. Eng. Chem. Res. 30, 12, 2576-2582.

Horstmann S., Jaboniec A., Krafczyk J., Fischera K., Gmehling J. (2005) PSRK group contribution equation of state: comprehensive revision and extension IV, including critical constants and function parameters for 1000 components, Fluid Phase Equilib. 227, 2, 157-164.

Hosein R., McCain Jr W. (2007) Extended analysis for gas condensate systems, SPE Annual Technical Conference and Exhibition held in Anaheim, California USA, 11-14 Nov, SPE-110152, SPE Reservoir Evaluation \& Engineering 12, 01, 159-166. 
Ihmels E.Ch, Gmehling J. (2003) Extension and revision of the group contribution method GCVOL for the prediction of pure compound liquid densities, Ind. Eng. Chem. Res. 42, $2,408-412$.

Jaubert J.N., Mutelet F. (2004) VLE predictions with the Peng-Robinson equation of state and temperature dependent $k_{i j}$ calculated through a group contribution method, Fluid Phase Equilib. 224, 285-304.

Jaubert J.N., Privat R., Mutelet F. (2010) Predicting the Phase Equilibria of Synthetic Petroleum Fluids with the PPR78 Approach, AIChE J. 56, 3225-3235.

Jöback K.G., Reid R.C. (1987) Estimation of PureComponent Properties from Group-Contributions, Chem. Eng. Commun. 57, 233-243.

Kesler M.G., Lee B.I. (1976) Improve prediction of enthalpy of fractions, Hydrocarb Process. 55, 153-158.

Marrero J., Gani R. (2001) Group-contribution based estimation of pure component properties, Fluid Phase Equilib. 183184, 183-208.

Merrill R.C., Hartman K.J., Creek J.L. (1994) A comparison of equation of state tuning methods, presented at the SPE 69th Annual Technical Conference and Exhibition, New Orleans, LA, SPE 28589.

Merrill R.C., Newley T.M.J. (1993) A systematic investigation into the most suitable data for development of equation of state for petroleum reservoir fluids, Fluid Phase Equilib. 82, 101-110.

Pedersen K.S., Christensen P.L. (2007) Phase Behavior of Petroleum Reservoir Fluids, Taylor \& Francis Group, New York.

Pedersen K.S., Thomassen Q., Riazi M.R., Daubert T.E. (1980) Prediction of the composition of Petroleum Fractions, Ind. Eng. Chem. Process Dev. 19, 289-294.

Pedersen K.S., Blilie A.L., Meisingset K.K. (1992) PVT Calculations on petroleum reservoir fluid using measured and estimated composition data for the plus fraction, I\&EC Research 31, 5, 1378-1383.

Peneloux A., Rauzy E., Fréze R. (1982) A consistent correction for Redlich-Kwong-Soave volumes, Fluid Phase Equilib. 8, 1, 7-23.

Peng D.Y., Robinson D.B. (1976) A New Two-Constant Equation of State, Ind. Chem. Fundam. 15, 1, 59-64.
Poling B.E., Prausnitz J.M., O’Connell J.P. (2001) The Properties of Gases and Liquids, 5th edn., McGraw-Hill International Edition, Singapore.

Riazi M.R., Daubert T.E. (1980) Simplify property predictions, Hydrocarb Process. 59, 115-116.

Riazi M.R., Daubert T.E. (1987) Characterization parameters for petroleum fractions, Ind. Eng. Chem. Res. 26, 755.

Ruzicka V., Fredenslund A., Rasmussen P. (1983) Representation of petroleum fractions by group contribution, Ind. Eng. Chem. Process Des. Dev. 22, 1, 49-53.

Sim W.J., Daubert T.E. (1980) Prediction of vapor-liquid equilibria of undefined mixture, Proces. Des. Dev. 19, 380.

Sinayuc C., Gumrah F. (2004) Predicting the critical properties of heptanes-plus in gas condensates: Genetic algorithms as an optimization toll, Petroleum Society's 5th Canadian International Petroleum Conference (55th Annual Technical Meeting), Calgary Alberta, Canada, 8-10 June.

Slot-Petersen C. (1989) A systematic and consistent approach to determine binary interaction coefficients for Peng-Robinson equation of state, SPE 16941, SPE Reservoir Engineering 4, 4, 488-494.

Soave G. (1972) Equilibrium constants from a modified Redlich-Kwong equation of state, Chem. Eng. Sci. 27, $1197-$ 1203.

Soreide I. (1989) Improved phase behavior predictions of petroleum reservoir fluids from a cubic equation of state, Doktor. Ing Thesis, Department of Petroleum Engineering Norwegian Institute of technology (NTH), Trondheim, Norway.

Whitson C.H. (1983) Characterizing hydrocarbon plus fractions, Soc. Pet. Eng. J. 23, 4, 683-694.

Whitson C.H. (1984) Effect of C7 + characterization on equations of state predictions, Soc. Pet. Eng. J. 24, 6, 685-694.

Whitson C.H., Anderson T.F., Soreide I. (1990) Application of gamma distribution model to molecular weight and boiling point data for petroleum fractions, Chem. Eng. Comm. 96, 259. Wong D.S.H., Sandler S.I.A. (1992) A theoretically correct mixing rule for cubic equations of state, AIChE J. 38, 671-680.

Manuscript accepted in September 2013 Published online in June 2014

Cite this article as: V. Uribe-Vargas, B. Carreón-Calderón, E. Ramírez-Jaramillo and M. Ramírez-de-Santiago (2014). Thermodynamic Characterization of Undefined Petroleum Fractions of Gas Condensate using Group Contribution, Oil Gas Sci. Technol 71, 5. 